\title{
The Exploration and Thinking of Teaching Decoration Art Design Creative Curriculum and Social Practice
}

\author{
YuNingchun \\ Jiujiang University,Jiujiang 332005,China
}

Keywords: Decoration art, Creative curriculum, Teaching software, Multimedia, Economy, practicability.

\begin{abstract}
To master the decoration art design knowledge of classroom teaching, it need to combine the practical application to the design, the decoration art design majors' students is put forward the basic requirements. Only through social practice, students fully contact with the market and understand the market, in order to make the design more economical and practical in the case of beauty, students can truly achieve the purpose of "knowledge and learning". This paper puts forward decoration creative art design curriculum based on the multimedia technology and teaching software, this paper separately expounds the indoor decoration art design, CI course and packaging art curriculum design, and teaching process should be combined with social practice, in order to provide some valuable reference for the classroom teaching and practice teaching of decoration art design.
\end{abstract}

\section{Introduction}

The decoration art design professional is closely related with the social production practice, and however content is often separated from social practice [1]. Due to the lack of social practice experience, students' design things are often use less, this product design is lack of practical, and they do not consider the practicability and economy of products in the design process [2-4]. At the same time, they do not consider the degree of creative design difficulty, but also they can not be integrated design products and practical application environment. Now, the market oriented economic model requirements that the teaching mode of the combination of classroom teaching and social practice closely should continue to improve and in-depth, to strengthen the students' art creation and professional technical ability [5-7]. Therefore, it is necessary to strengthen creative research and development of decoration art design courses social practice, in order to improve the modern teaching ability of decoration art design courses.

\section{The Superiority of the Decoration Art Design Curriculum Teaching and Social Practice}

Combined with social practice, decoration art curriculum can effectively provide a commercial environment work experience for students [8-10]. Through the use of software and multimedia technology, students can not only get the training and learning, but also can improve practical ability, so as to can improve students' comprehensive [11-13]. Through the study of course, students can not only understand the art design thinking and basic theoretical knowledge, but also can transform the abstract art creativity into the actual product model [14]. In the teaching process, teaching contents are mainly on the virtual subject, social production practice is not close, the design something is easy to the lack of practicability and social experience, and product design does not fusion with practical application [15-17]. For example, students do not consider design cost and the realization of the degree of difficulty for the art design of the printing products, so as not to good printing effect. Through social practice, students can have further understanding for the design things' practicality and economy. 


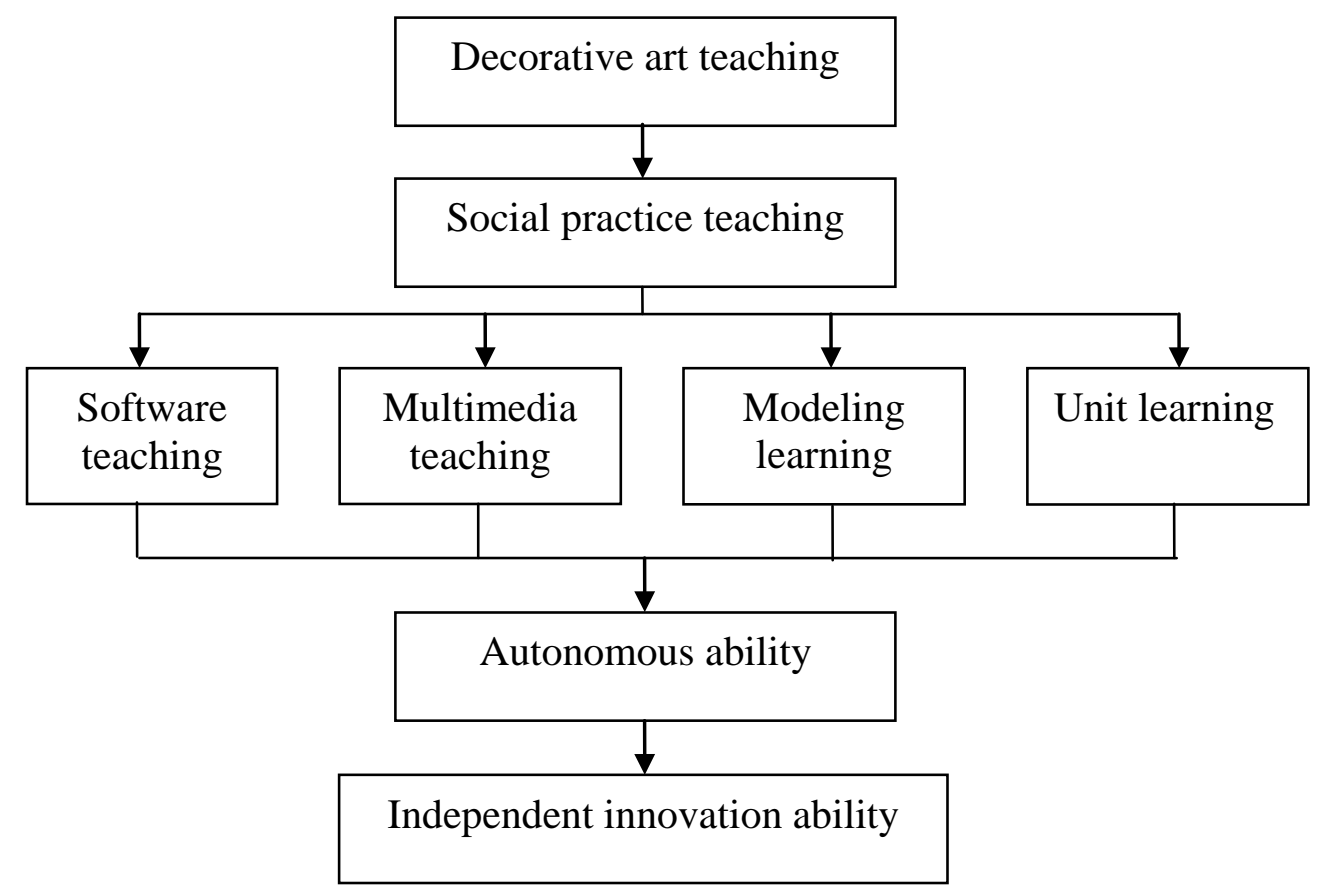

Fig. 1 Decorative arts teaching and social practice creative curriculum framework

The combination of social practice and class teaching is a necessary way to poor students' hands-on ability. As shown in Figure 1, it shows that combined with decoration art teaching and social practice, the main teaching content of creative curriculum system is teaching software, multimedia teaching, 3D modeling teaching and production practice, which can effectively improve the students' independent innovation ability and practical ability. Combined with art design and practice, its creative courses can overcome the traditional education taking knowledge teaching as the goal and memory dominant thinking disadvantages, which can improve the actual teaching effect.

\section{Interior Decoration Art Design Teaching and Social Practice Creative Course Research}

In the creative design of decoration art classroom, it is the combination of social practice and class, but it is ultimately reflected in the form of classroom teaching activities [18]. However, in the specific teaching implementation process, the creative design is embodied in the main courses. In order to combine indoor decoration design and concrete practice, this study is design software commonly used by interior design studio as an example, combined with specific project, to carry on the teaching practice for student's software, and then enabling the student to have the preliminary ability of operation.

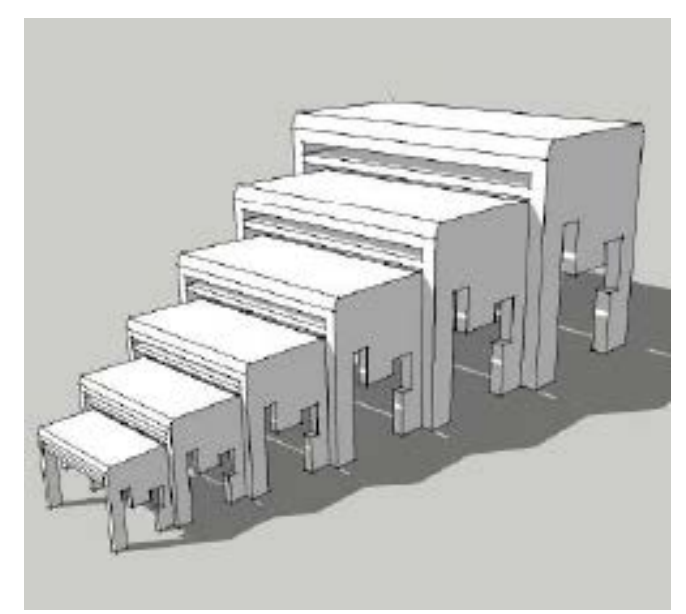

Fig. 2 The gradient three-dimensional graphics of indoor decoration design

For the interior decoration design teaching, interior gradient three-dimensional graphics is commonly used as a teaching model, and its gradient mainly includes furniture stereo pattern, chairs lines and decorative pattern and so on. Through the gradient of the graphic, we can add different 
rhythm and rhyme, and this process can be achieved by extending the 3D modeling software. In the teaching process, we can use 3D software to operate directly on the model, and it can increase the visual process of teaching, making the abstract teaching into practice.

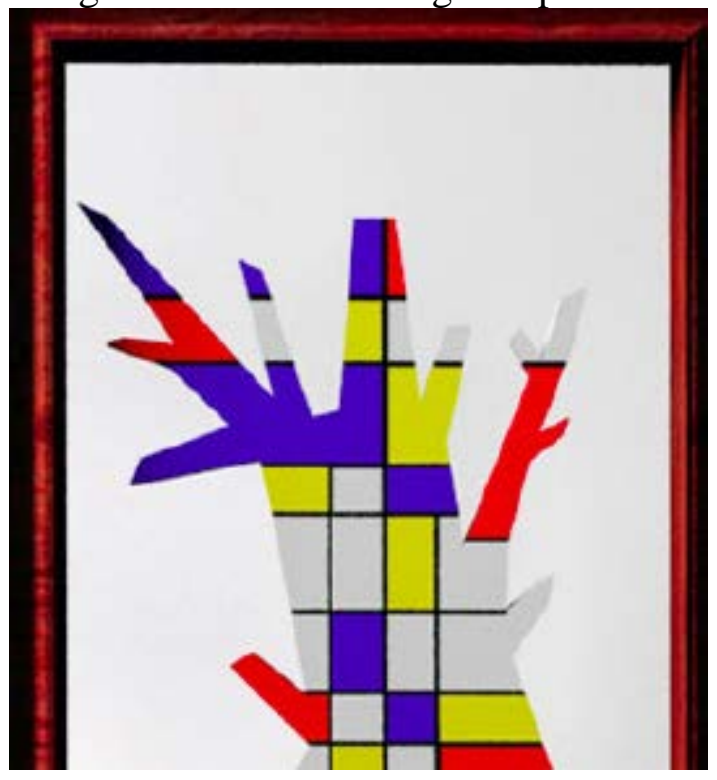

Fig. 3 Color tree renderings

Color tree effect is arranged a variety of color in an object, and color layout should be combined with the space. In the actual design process, color flexible use is not static, but to flexible application according to the actual environment and objects, which adds to the difficulty in your interior design. So in the teaching process, in order to make the abstract theory into the specific teaching content, we can use the teaching software, let the students through own hands-on, introducing their individual colors into the learning process, so as to improve the interest in learning and enhance the learning enthusiasm.

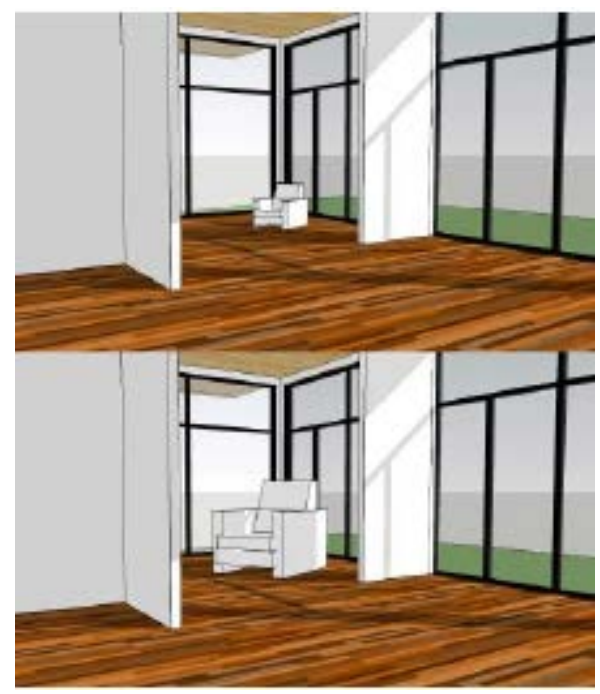

Fig.4 Stereo proportion contrast effect of furniture

In the teaching of furniture stereo proportion contrast effect, the shape and size of furniture decides the number of interior decoration. In a large indoor space, a small furniture layout as shown in Figure 3 will appear to be very spacious living room. However, the smaller indoor space puts big furniture, it will not only occupy space, and it will affect the overall effect of the space. So, the arrangement of the space furniture is combined with three-dimensional space to achieve proportion changes of furniture in the teaching process, and we can be combined with the practice teaching software to reflect the furniture proportion, so as to enhance the teaching effect of interior decoration artistic design. 


\section{Study on the Integration of Anther Teaching Activities and Practice in the Decorative Art Design}

CI curriculum and practice combination. In order to improve the students' ability of learning and communication, CI course is mainly the ability of practice and operation as the main teaching content, and by improving students' organization, planning, actual operation ability and comprehensive quality, so CI courses need to the combination of social practice.

Firstly, course should play the main role of students to in-depth business visit and collect all kinds of information, which has profound significance for the creation of late. Students can go through the information collection, there are some pointed creations, and we increase the student's responsibility in the creation [19]. Secondly, teachers should keep in touch with the latest creation, which can analyze and sort out ideas. If there is a need for local businesses in this area, the students will be introduced into the social practice system based on the actual project, to participate in the practice of enterprise projects [20]. Teachers can find different enterprise project, the research of the project is introduced into the curriculum, teaching art design need to pay attention to matters by absorbing the good ideas and means, so as to improve the students' design ability and creative ability, and to adapt to the needs of society and enterprises.

Packaging design curriculum and social practice. With the continuous development of economic globalization, the packaging industry is taking the consumer as the center and personalized design as the basis, so as to reflect the innovation of modern art design. Under this kind of background, the teaching of art design needs to improve the students' ability of design and innovation as the goal, expanding the students' scope of knowledge, so as to be able to adapt to the challenges and development of society. But in the current course, because the knowledge involved is relatively narrow, teaching contents are lack of unified arrangement. Therefore, the current course presents knowledge of aging, outdated teaching methods and other defects, which leads to poor students' practice ability and weak research ability.

According to development of the packaging art design teaching content, we should take modern new technology and personalized design as the basis, new curriculum contents establish perfect teaching base, and students understand the packaging printing, modern new materials and other related knowledge. To cultivate students' creative consciousness, teachers inject new ideas into talents training through summarizing the experience of design, to find their weakness in practice. For the practice and innovation of packaging art design course, many schools have been carried out, such as the moon cake packaging design course of Nanjing art Institute, it introduces market demand into the classroom. After students are full investigation on the commodity market character and the basic needs of customer, combined with the characteristics of the moon cake packaging art design, students carry out curriculum design, so as to train the students' ability of design thinking and improving the students' innovation consciousness. Finally, students bring to the printing plant, the design idea will be turned into production, thereby enabling students to understand the entire process from design to product, enhancing the curriculum of social practice, and effectively improving the students' ability of social practice.

\section{Summary}

The theoretical teaching is more professional theory, and social practice is to enrich the students' social experience and academic knowledge, cultivating their independent innovation spirit and practice ability, and improving their comprehensive quality. This study proposes decoration creative art design courses based on multimedia technology and software teaching, and separately elaborates indoor decoration art design, CI course and packaging art curriculum design, and teaching process combines with social practice, focusing on the interior decoration art design and the course content of combination of multimedia and software teaching, to improve students' practical ability and innovation ability as training objectives, thereby improving the modern decoration art design courses teaching system. 


\section{References}

[1] Y.B. Long. Reform and practice of advertising design and production major curriculum system in higher vocational colleges -- taking Liuzhou vocational and technical college as an example. Journal of Liuzhou vocational and technical college, 2014, 11(4): 104-107.

[2] L. She, Y.B. Long. The exploration of teaching mode for art design training studio --discussion on innovative ideas and teaching mode reform. Higher education forum, 2014, 141(7): 111-113.

[3] Y.B. Long. Study on the cultivation of students' creative thinking ability in computer art design course. Journal of Liuzhou Vocational and Technical College, 2014, 8(2): 44-46.

[4] C.W. Hu, J. Wan. Study on the studio teaching mode of art design in higher vocational colleges. Vocational and technical, 2014, 104(4): 4-5.

[5] H.J. Yu. The exploration of art design specialty studio system in higher vocational college. Journal of Zhongshan University, 2014, 21(3): 54-56.

[6] W.Z. Yu. The exploration and practice of the teaching mode for the art design major studio system in higher vocational colleges. Journal of Zhejiang business technology institute, 2013, 7(2): 76-96.

[7] L.Y. Song. The psychological characteristics of middle school students in English teaching [J]. Educational exploration, 2014(3): 55-56.

[8] J. Song. English teaching should pay attention to the students' emotion. Chapter, 2013(5): 92-93.

[9] Y.M. Zhu. New thinking on improving students' learning interest and motivation in English teaching. Chinese off campus education (Theory), 2013(4): 105-106.

[10] Y. Yang. Advantages and disadvantages of multimedia teaching in English teaching. Journal of Jilin radio and television university, 2014(6): 146-147.

[11] Y.H. Zhang. Study on the dynamic evaluation model of college English network writing teaching. Foreign language circle, 2014(4): 73-81.

[12] X.Q. Wang. Theory and practice of higher mathematic stratified teaching model. Jilin education, 2014(11): 20-21.

[13] Y.S. Li. Study on the classification and cultivation model in China's college postgraduate education. Journal of Hefei University of industry and Commerce (SOCIAL SCIENCE EDITION), 2014, 21(3): 64-65.

[14] Q.Y. Lou. Graduate students' employment decision based on SWOT analysis. Higher agricultural education, 2014(8): 80-83.

[15] L.L. Sun. Discussion on graduate students career planning. China science and technology information, 2014(17): 161-162.

[16] J.H. Cao. Investigation and analysis of graduate students career exploration behaviors and job hunting behavior, 2015(12): 41-44.

[17] Z.Y. Sun, M. Dong. Analysis and countermeasure research on college students career planning based on attribution theory. Journal of Anyang College, 2015(3): 21-24.

[18] F.Y. Li. Application and thinking of multimedia in English teaching. China information technology education, 2014(8): 43-44.

[19] G.F. Zhang. A preliminary discussion on the task driven approach teaching mode. Education and occupation, 2014(4): 80-81.

[20] W. Yu. The task-based teaching is an effective way to achieve the of the new curriculum goal teaching. Science and technology studies, 2014(2): 126-127. 